Stream: Inspiring Critical Thought

2019, Vol 11(1), 24-30

(C) The Author(s), 2019

http://journals.sfu.ca/stream

\title{
Urban-Rural Mobility through the Lens of Food Documentary: A Case Study of "A Bite of China: Season Two"
}

\author{
Yao Lu \\ Shanghai Academy of Social Sciences, China \\ Xiaoxiao Yang \\ Shanghai Jiaotong University, China
}

\begin{abstract}
The combination of traditional Chinese food processing techniques and contemporary commercial food production forms the main topics of "A Bite of China: Season Two" (ABOC-2). Built upon the success of its first reason, ABOC- 2 has achieved a record high TV rating among domestic audience and also made history by becoming the best-selling Chinese documentary overseas. By examining the individual experiences of migrant workers shown in ABOC-2, this paper discusses the important role of rural Chinese cuisine in maintaining the urban-rural mobility of contemporary China. We argue that one major storyline of ABOC-2, in which migrant workers maintain their inherent economic and social connections with their native countryside through cooking and consuming hometown dishes, sheds light upon migrant workers' active resistance to the partially rational yet overly standardized ways of urban living. By showing respect to rural traditions and culture, ABOC-2 has successfully promoted the dignity of Chinese migrant workers and depicted their spiritual plight in contemporary China's drive toward modernization.
\end{abstract}

\section{Keywords}

contemporary China, urban-rural mobility, documentary, Chinese traditional cuisine

\section{Introduction}

"A Bite of China" (hereafter as "ABOC", with ABOC-1 referring to its first season and ABOC-2 referring to its second season) is a food documentary series produced by China Central Television (CCTV). Being the first series filmed with HD equipment in China, ABOC was regarded as an important production that CCTV pinned great hopes on. The shooting of ABOC started in March 2011 and with over 60 sites, its production almost travelled the whole country. Originally released May 2012 on CCTV, the first episode of ABOC-1 hit an ordinary rating of $0.5 \%$, which set a record that even overshadowed popular TV shows of the same period (Chen, W., 2012 May 23). This record-breaking success continued in international sales, with a single episode of ABOC being sold for 40,000 USD in syndication. Over 100 countries and regions broadcasted the series. Two years later, ABOC-2 made a success again. In the first round of syndication, a single episode was sold for up to $\$ 350,000$, which set a record for China`s overseas documentary publishing (Chen, H., 2014 April 23).

The great success of $A B O C$ also indicates a notable shift in Chinese documentary narrative. The series' director, Chen Xiaoqing, has took a great initiative to change the condescending attitude and 
grand narrative that were frequently found in China`s mainstream documentaries. In his words (Chen, X., 2014 May 10), the narrative needs to be changed from "to show what you see to the audience" to "show the life itself of the one in the camera". During the filming of ABOC, Chen Xiaoqing initiates such change by focusing on the historical inheritance and spiritual significance embedded in the preparation and consumption of Chinese traditional cuisine, which further reveals how food culture interacts with specific historical background, family environment and individual state in contemporary China (Wan, 2014).

Comparing the narratives of $\mathrm{ABOC}-1$ and $\mathrm{ABOC}-2$, it becomes evident that that the latter begins to focus more on everyday living behind Chinese food culture. According to Chen Xiaoqing, this narrative change is primarily driven by his refusal to show the subjects in an empathy-lacking manner. Instead, Chen Xiaoqing insists that food should be considered as a medium through which a deep understanding of everyday experience could be expressed.

Following Chen Xiaoqing's comment, this paper examines the migrant workers and their connections with Chinese traditional cuisine shown in ABOC-2. By revealing the current urban-rural migrant relationships embedded in these individual stories, we argue that nostalgia expressed through cooking and consuming Chinese traditional cuisine presents an important site for migrant workers' active resistance to the partially rational yet overly standardized ways of urban living.

\section{Literature Review}

Due to the great success of ABOC-1, many scholars and experts have researched the documentary with a number of dissertations and papers from several perspectives. From a mass communication studies perspective, ABOC's success was credited to its communication effect, appeal, and influence (Yin, 2012). While digging specifically into the communication effect, Wang (2014) selected related Weibo posts of ABOC-1 to analyze the documentary's presence in new media. Her analysis suggested a gradual wavy communication process directed by key opinion leaders, which attracted widespread audience and attention through word-of-mouth communication. It finally became a social public issue synergized by various parties. Yet the differences in types of new media communication relating to ABOC-1 have not been discussed.

From a cultural study perspective, Lv (2013) argues that the innovative use of an internationally appealing narration offers an inspiring way of thinking for China's cultural communication and national image. By adopting the Encoding-Decoding theory of Stuart Hall and the cultural connotation analysis of Roland Barthes, Lv considers ABOC as a successfully knocking on the proverbial international door of documentary filmmaking, which offers a positive outlook for the future. Likewise, Wan (2014) insists that, following American scholar James Carey, communication is a ceremonial process of creating, changing and shifting a shared culture. This process constitutes a new way of sharing ceremony and is an articulation of Chinese tradition, morals and culture (Shang, 2014).

It should be noted that although the rethinking of fading notions, values, and cultural traditions is meaningful, ABOC-2 has also been criticized for going in the opposite direction and ignored the beauty of food and taste. As a food documentary, the balance between people and food had been a long-lasting discussion since the beginning of the first episode. Although ABOC-2 inherited the narrative style of $A B O C-1$, its theme has completely shifted from food to people, from exclusive to open and abstract, and it became more humane and cultivated by exhibiting an obvious shift of narrative focus. Controversies have arisen because some scholars hold that the value and success of ABOC-2 is articulated in the sociality, harmony, substantiality and humanity of food based on analysis of the stories' value, voice and techniques (Shang, 2014). Meanwhile, some people criticized the clichéd promotion of family unity, which has been frequently employed by other entertainment programs to 
appeal to their audience. In addition, the relationship of camera and food is not as intimate and intense as ABOC-1. ABOC-1 was the result of over-emphasis on family and bonding (Zhao, 2014).

It can be seen that, no matter whether from the mass communication or a cultural study perspective, or from a text study versus a strategy study perspective, few efforts have been attempted to discover the historical or real-world problems implied or displayed by the food documentary series. Textual analysis of Chinese documentaries remains in short supply. Along with the de-politicization, marketization and commercialization drive after the 1990s, urbanization has accelerated as migrant workers flood into the cities. The inequality in political, economic and cultural fields has not only intensified the gap between city dwellers and those living in the countryside, but also led to the split of rural and urban areas. It creates severe ethnic conflicts and a crisis of national culture. The considerable amount of time given to the portrayal of rural ethnic minorities and individuals was not only a rebellion against the Hollywoodization of the present film and broadcasting industry, but also symbolized a return to the prominence of ethnic and national identity and tradition. As a hidden clue, food served to bind the political entity of the Han people as they coexisted with other ethnic groups.

In light of the above context, this paper discusses how the second season of the series displayed the beauty of rural Chinese cuisine in a social context of the current rural-urban relations and population mobility. Also, it presented Chinese farmers and their destiny in the present time.

\section{Methodology}

Text-reading is an important research method in film study. Text itself is of vital importance, which could be analyzed form several theoretical perspectives, notably semiotics, psychoanalysis, post-colonial study, post-structural analysis, and Marxism. These theories have been adopted to explain modern and contemporary literature works and television arts, including documentaries. The deep connotations of the documentary texts could also be studied within the social structure and historical context of China. While ABOC-1 presented the food, ABOC- 2 addressed the lifestyles of the subjects. The humanistic significance of the traditional food production techniques, as well as the commercialization of food became the main concerns of ABOC-2. It painted a picture of the comprehensive social scenario in contemporary China. Accordingly, this paper focuses on how the documentary represented the significance of Chinese cuisine in rural areas against the social context of rural-urban relation.

\section{Urban-rural Mobility in Contemporary China}

While ABOC- 1 addressed mass-produced food, ABOC-2 has "gone out of the city." The outside is not just a simple and objective geological space; it is more of the extent to which a whole life is squeezed by the modernization and urbanization with a rational, cold and calculated core. In general, modernization inevitably involves the overall impact to the traditional way of material production and social institution, such as industrialization (the emancipation of labor), urbanization (core family), and emergence of the modern nations (nationalization of family member) (Chen, Y. 2012). Therefore, individuals moving from rural areas to the cities would inevitably encounter new challenges in knowledge structure, social values, and ways of thinking. Henri Mendras (1991) pointed out that the major problem that the world has proposed for social sciences during the second phase of the 20th century is that there are two billion farmers standing in front of the entry of the industrial civilization. That's because in the first five decades of the 20th century, "compared to the rapid development of the industry, the slow development of agriculture offers a secure, stable and balanced impression. Against the fetish of the industry, the farmers with good sense seemed to be eternal; the city and the 
industry attract all the power, but the countryside has always nurtured a tranquil, blissful, secure and eternal Arcadian dream." In contrast, urbanization and modernization has broken this precious balance and rocked the whole social structure.

To put this concept to the urbanization experience of China, it could be found that reform and opening-up has set free the attraction of the city from whom the rural population that has long suppressed. This urbanization drive was aided by the founding of a socialist market economy, the elimination of the previous household registration system and the advocating of the export-oriented economy in coastal areas. From the beginning of 1980s, the surplus of rural population and the lack of urban labor have resulted in a flood of migrant workers to the city. According to China's sixth demographic census, there were " 221 million floating population in 2010, taking up $16.53 \%$ of the China population" (The research group of the State Council, 2014, p. 169).

However, during this process, the dual-track system of public welfare behind the household registration system offered both pros and cons. The positive involved the nation's development while the negative aggravated its economic and social burden during this period of rural population urbanization. At the individual level, urban-rural migrants faced a lot more serious pressure for finding a means of living and discovered the need to obtain economic capital out of more labor. On the other hand, the lack of social public service pushed this group back to its native family and neighborhood for assistance in such cases as childcare. Individual choices in such social economic circumstances had undoubtedly strengthened their intertwined connections with the countryside, while achieving a revival of rural values and norms in the urban space. Furthermore, these circumstances strengthened the nostalgia in their hearts. These circumstances have defined the complex attitude of Chinese urban-rural migrants when facing the city and the countryside. If not going out to the city, they would hardly stand out. However, like a shadow, nostalgia would forever mark their lives.

\section{The Representation of Traditional Rural Cuisine in Urban Space}

The inheritance of traditional culinary techniques in different spaces took up the majority of the themes and subjects in ABOC-2. We should note that the documentary depicted mass-produced and processed food and its consumption in a sharp contrast with its traditional equivalence. In the last episode Breakfast, Lunch and Dinner of ABOC-2, the leading roles were those of two migrant workers on the assembly line. Yang Yuanyuan was a grassroots worker and $\mathrm{Xu}$ Lei was the manager. Their different ways of food consumption exemplified each migrant's local traditions in food preparation as cooking methods are carried over to an urban environment. Yang was a newcomer in the factory. Her work was relatively basic, which best exemplifies the mass production, standardization and deindividualization of modern industry. Yang worked more than seven hours a day, her work was simple and repetitive on a huge industrial assembly line where she performed one operation every 5 seconds 5,000 times a day. Apart from work, the mass-production characteristic lies also in food and other aspects of their everyday life. The food for Yang is also prepared in a central kitchen from an assembly line. Although she shed a smile while enjoying her food, the consumption of mass-produced food was still extremely de-individualized and dominated by external functions. There were 20 restaurants of different sizes located in the industrial park and the largest could serve 2,000 people at the same time. For her spare time, we just were just shown Yang on screen having a short break from work and meeting with friends. In general, the factory provided grassroots workers a typical lifestyle that was standardized, de-personalized and strictly in accordance of what is expected for all factory workers. Coupled with the high pressure and fast speed of their jobs, young people must be able to cope with the shrinkage of spiritual life and leisure time. 
In comparison, due to their relatively rich work experience and good economic conditions, Xu Lei and his wife Wen Fei lived outside the Foxconn industrial park. They could realize the nostalgia by cooking homemade dishes and find their cultural identification and personality. In the story, Xu started to work when he was 16 or 17 years old. Now at 28, he had worked at Foxconn for 11 years. For his efforts, $\mathrm{Xu}$ is a part of the management for a highly standardized mass-produced product. He needed to comply with the rules on keeping confidentiality as part of his employment at the manufacturing plant. He was faced with the overall transformation from rural life to an urban resident. Due to economic pressure, his children were being raised in his hometown. In their tiny kitchen, when two people passed each other, they had to nudge their way around by turning their bodies. Nevertheless, it was in the narrow confines that this couple, born in the countryside, began to move the traditional food from their hometown in Hunan province to their urban life. In the documentary, Xu Lei enjoyed the salted duck eggs prepared by his mother-in-law in the distant hometown in Hunan province. His narration stated that the taste of the homeland had a special magic, which united the family scattered across time and space. This view was a legitimate example of individuals resisting the difficulties in life and existence in the drive towards modernization.

As a detailed illustration of individual spiritual resistance and breakdown of the difficult situations under the stress of urbanization, the documentary elaborated upon the preparation techniques including the process of marinating and drying fish and salty duck eggs. Compared to the life of Yang Yuanyuan and other grassroots factory workers filling the assembly line, the documentary exposed that fact that urbanization in physical space, external conditions and lifestyle did not equate to a meaningful and valuable life. In the modern urban space that featured high pressure, high intensity and high stimulation, although individuals could forge innovation and viability that a slow, tranquil and stable rustic life could never provide, a person's spiritual contentment could not simply be accomplished by going into the cities. Just as the criteria for food is more than simply being safe and nutritionally well-balanced, contentment demanded more than urbanization. For most migrant workers in the urban-rural mobility, their spiritual contentment was not dependent on the consumption of cultural fine goods with high artistic level and rich spiritual connotation. It was through traditional everyday life with which one is familiar that one's ethical emotions get externalized in a natural way and finally reaches a spiritual solace.

To a large extent, the modern urban lifestyle and value system repressed the individual's sense of self and his rural sensibilities. In a rural society, the relatively freedom of activities had to be regulated in the modern urban space. One's life had to face much more uneasiness, confusion, frustration and upset than ever before, which resulted in a spiritual plight of finding nowhere to resolve emotions. The practice of traditions in the urban space helped find a way out by presenting affirming attitudes of inclusion. Although the rural traditions might not have worked that much from a utilitarian perspective, they provided a feasible way to deal with the uneasiness of living in the urban space.

\section{Recognition of "Nostalgia": Exhibition of Traditional Cuisine in Rural China}

Although stable and peaceful rural areas yielded an environment which emphasized a lifestyle of few unknowns, human nature often demanded that individuals chose to leave the countryside for the city in order to obtain greater self-fulfillment. It can be argued that, to a great extent, the spirit of traditional culture in rural areas offered a spiritual weapon to resist modern materialism one-sided utilitarianism. It could be argued that new residents, consisting of mostly urban-rural mobility, articulated their response to the value of urbanization and modernization by voluntarily creating bits of rural traditions in the urban space. Their preparation and consumption of rural food after returning to the countryside reflected the rethinking of their own traditions. The processing and consumption 
of food in the rural space was not just scattered noise against the backdrop of the modern city, but rather it was a window in understanding the overall rural lifestyle. The first episode of ABOC-2 depicted the real experience of Yu Gaoli and her husband who returned home from the Guangdong city to take care of their farmland. The couple's hometown was located in Qiaogang, the most remote village in the southeast of Guizhou Province. During the half month spent in their hometown, Yu totally reverted to the traditional mother's role in the local rural society of this ethnic minority. The documentary recorded a considerable number of cultural features and details in this rural society of ethnic minorities. The daughter brought a mirror and dressed herself by the riverside in traditionally plain ethnic clothing. She wore a hairstyle common of her ethnic group. The process of cooking the glutinous rice fish and Leishan fish sauce was also part of the process for regaining identity. It represented the shift from a migrant worker to a mother and a hostess in a rural family. The process of catching and marinating the fish is like a game between Yu and her children. However, the preparation of fish sauce called for all the villagers to work together. The organization of labor in the local community marked a sharp contrast with that in a modern industrial society.

The time that Yu spent at home was half a month, which equaled the time for making the fish sauce. When the fish sauce got ready to be served, it was time to return to the city. In the episode, the family members sat together and enjoyed their last reunion dinner. The voice-over announced that it was the most delicious reunion in the year, and it was also destined to be filled with mixed feelings. Even in the rural areas, where the traditional was stronger than the modern, the production and consumption of food was still an integral part of the most important characteristics of the cultural. The distribution of food was an important aspect of traditional daily life and order in China. The concentrated efforts of the family in preparing food, as well as the rules and manners of producing and consuming food, was also an important way of emoting, understanding and ultimately complying with local values and codes of conduct. It was through this process that migrant workers have taken the initiative to return to their local rural culture and traditions.

In another story, Cheng Shikun, a Chinese living overseas for a decade returned to fulfill his duty in a ceremony commemorating the memory of his ancestors. He asked that family members "use up all the talents of the good local cook." The feast in Daxia Village, City of Quanzhou, Southeast Fujian Province had explicitly revealed the complementary relationships between eating and the traditional folk ceremony and local beliefs. Similarly, in an episode describing the local family eating the local bread of Shanxi province, the voiceover stated, "no matter where you are, when it is an important moment for the family, the Chinese would gather by their table and feel integrated and empowered by the same blood and union. This is the secret of a family surviving through difficult times."

The Director Chen Xiaoqing confessed that, when filming the documentary, he hoped to find out how the Chinese people lingered around their traditions. He wanted to see how people deal with rapid changes and keep from panicking. Most of young peasants have become migrant workers, while the old and the children stayed behind. This situation also posed questions as to the inheritance of rural traditions in the urban space. Not only those born in the countryside would identify with rural life. Urban residents also expressed an urge to live in rural lands. The importance of this nostalgia should never be overlooked.

\section{Concluding Remarks}

The production team of ABOC cited the slow food movement of Carlo Petrini as their inspiration, while Japanese documentary master Shinsuke Ogawa has had a significant impact on China's independent documentary directors in the 1980s and 1990s. They have something in common: the 
cultural rethinking on the basis of renewed inheritance and the homage to traditions. The homeland was pitted against the linearly progressed grand narration and the rational and utilitarian social thought.

Urbanization is not a simple process of rural population, resources, and capital flowing to urban spaces. It brings the overall transition of individuals' ways of life and cultural values. Realizing the balance between the modern urban life and the memory of cultural traditions while maintaining individuals' inherent cultural right and spiritual freedom have become an underlying question of urbanization that can neither be quantifiably measured nor simply ignored. Yet, this cultural right is not illustrated by universal and highly abstract concepts.

The beginning of rites lies in the diet. The production and allocation of food is a significant part of the social system in Chinese traditional culture as well as a vital component in the rural culture's indoctrination. Whether it is the sporadic occurrence of traditional food in the urban area, or the availability of preserved traditional food, the significance of using documentaries to represent traditional food in a contemporary context lies in that they go far beyond a simple utilitarian presentation of "filling the stomach" or "made to someone's taste." Individuals achieves spiritual enjoyment through the process of making or consuming familiar food. Traditional food activates migrants' emotions and form positive collective rural memories to resist the depression, anxiety and powerlessness in their hard life far from home.

\section{References}

Chen, H. (2014, April 23). Exploring “A Bite of China: The second season might have gained over one hundred million. Retrieved from http://money.163.com/

Chen, W. (2012, May 23). The rating of "A Bite of China" is as high as BBC documentaries. Retrieved from http://ent.sina.com.cn/

Chen, X. (2014, May 10). Interview with Chen Xiaoqing. CCTV 1 Voice. Retrieved from http://tv.cntv.cn

Chen, Y. (ed.) (2012). The logic of urban China. SDX Joint Publishing Bookstore, China: Shanghai.

Mendras, H. (1991). The end of peasants (Li P. trans.), China Social Sciences Press, China: Beijing.

Lv, J. (2013). Research on coding of dietary culture of "A Bite of China." MA Thesis, HeBei university. Retrieved from https://www.cnki.net/

Shang, W. (2014). How is the story told by "A bite of China". Contemporary TV, 2014(9). Retrieved from https://www.cnki.net/

The research group of the State Council (eds.) (2014). The path, mode and strategy of China's new pattern of urbanization. China development Press, China: Beijing.

Wan, N. (2014). Ritual and spiritual communication of "A Bite of China". China Television, 2014(10). Retrieved from https://www.cnki.net/

Wang, W. (2014). Research on microblog communication phenomenon of "A Bite of China." MA Thesis, Liao Ning university. Retrieved from https://www.cnki.net/

Yin, H. (2012). Elegance and vulgarity can be appreciated and praised together. News and Writing, 2012(7). Retrieved from https://www.cnki.net/

Zhao, T. (2014). Comments on "A bite of China". China Radio \& TV Academic Journal, 2014(8). Retrieved from https://www.cnki.net/ 